Article

\title{
China Building Energy Consumption: Definitions and Measures from an Operational Perspective
}

\author{
Wei Wei ${ }^{1}$ and Ling-Yun $\mathrm{He}^{2,3,4, *}$ \\ 1 College of Economics and Management, China Agricultural University, Beijing 100083, China; \\ weiweismileatlife@163.com \\ 2 School of Economics, JiNan University, Guangzhou 510632, China \\ 3 Institute of Resource, Environment and Sustainable Development Research, JiNan University, \\ Guangzhou 510632, China \\ 4 School of Economics and Management, Nanjing University of Information Science and Technology, \\ Nanjing 210044, China \\ * Correspondence: lyhe@amss.ac.cn \\ Academic Editor: Chi-Ming Lai \\ Received: 18 February 2017; Accepted: 17 April 2017; Published: 25 April 2017
}

\begin{abstract}
China building energy consumption (BEC) has been gradually derived and also sparked attention. However, something worth discussing is estimating the BEC based on the definition of life cycle or building operation. In addition, there exists discrepancy in the previous studies and the real status of BEC has not been known well. In order to settle the disputes over the calculation of $\mathrm{BEC}$, this paper establishes an appropriate accounting method of building energy to present the BEC situation in China and lays the foundation for policymakers to develop appropriate energy saving policies. Meanwhile, this study attempts to clarify the BEC to help policymakers assess the effect of environmental policies. Using the method in this document, we find that the energy consumption of buildings just accounts for $15 \%-16 \%$ of the final total energy consumption in China; by contrast, the previous studies usually have double accounting through a top-down approach if central heat supply of buildings was taken into additional consideration.
\end{abstract}

Keywords: building energy consumption; operation; life cycle; China

\section{Introduction}

Energy consumption has a severe impact on the environment. For the past three decades, there has been consistent growth in total primary energy consumption and carbon dioxide emissions throughout the 226 countries and regions (see Figure 1) [1]. The global environmental problems caused by energy consumption not only hinder the sustainable development of an economy but also threaten the survival and sustainable development of human society. Therefore, more attention has been focused on energy saving and emission reduction.

The energy consumption from building falls between $20 \%$ and $40 \%$ in developed countries. This consumption far exceeds the ratios of the energy consumed in the industrial and transportation sectors [2]. The building sector currently accounts for about one third of total final energy use worldwide [3]. Energy consumption of buildings has come into focus all over the world, especially in China, where population and urbanization have been increasing demand for building and energy continuously during the last three decades. It is equivalent to the total energy consumption in the Middle East, twice as much as the consumption in Africa, and equals the total consumption of Japan and South Korea combined [4]. It follows that the BEC is one of the major contributors to domestic energy shortages in China, as well as to global environmental externality. 


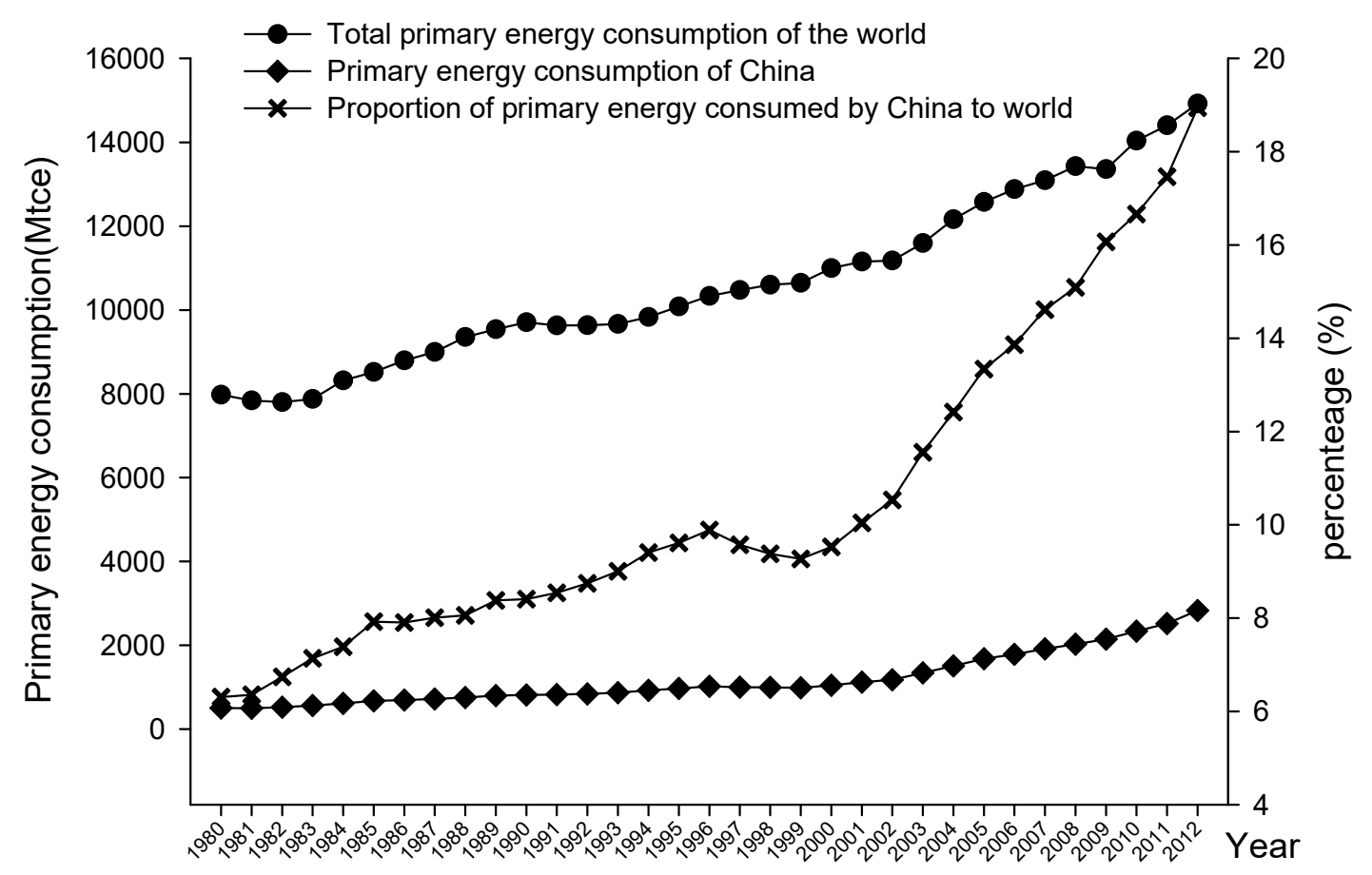

Figure 1. The total primary energy consumption during 1980 to 2012.

According to the National Bureau of Statistics (NBS) of China, from the year of 2000 to 2014, the total energy consumption of China has been scaled up to 4160 million tons of coal equivalent (Mtce) and keeps increasing dramatically (see Figure 2). As the rapid urbanization, together with the boom of the construction industry, billions of square meters of housing were completed year by year from 2000 to 2014 (see Figure 2). The BEC becomes the second largest in terms of energy use in China [5]. Nearly half of the world's new building construction is in China [6]. In 2015, Chinese president Xi Jinping, during his state visit to the United States, emphasized promoting the construction of the Sino-US energy conservation fund project to carry out the work of building energy conservation [7]. In China, BEC has caused the widespread concern from the government and the general public, but the state of BEC of accounting remains to be clarified.

Statistics on energy consumption in China is so different from those in other countries that additional calculation is required to make an informed and realistic evaluation of China building energy consumption. In the USA, Energy Information Administration (EIA) is responsible for the scientific development of public buildings and residential buildings energy consumption survey. Therefore, the general situation of BEC, energy consumption data and characteristics of buildings with different types and functions can be learned. The BEC statistics are available from the Residential Buildings Energy Consumption Survey [8] and Commercial Buildings Energy Consumption Survey [9]. In Japan, energy is consumed largely by the industry sector, the transportation sector, and the livelihood sector. The livelihood sector, including household and business, can be calculated as a part of the total BEC. In Indonesia, the quantity of energy consumed in household, commercial, industry, and transportation sectors is accounted separately; and the household and commercial sectors are generally summed up as the BEC [10]. However, through analyzing the energy statistics in China, there are no specific statistics on the BEC. Therefore, one of the burning issues of BEC is that the quantities of energy consumed by buildings are diverse by different approaches.

There are huge differences among the statistics of BEC from previous research. It has once been accepted that the BEC accounted for $27.4 \%$ of national total energy consumption; however, Yang et al. [11] argue that the energy consumption of the construction industry is regarded as BEC and 
that there still exists ambiguity between the concept of intermediate and final energy consumption. As Table 1 shows, there is a wide variety in the ratio of the BEC depending on different definitions, classifications, approaches, and calculations.

Table 1. Building energy consumption situation of different statistics in China.

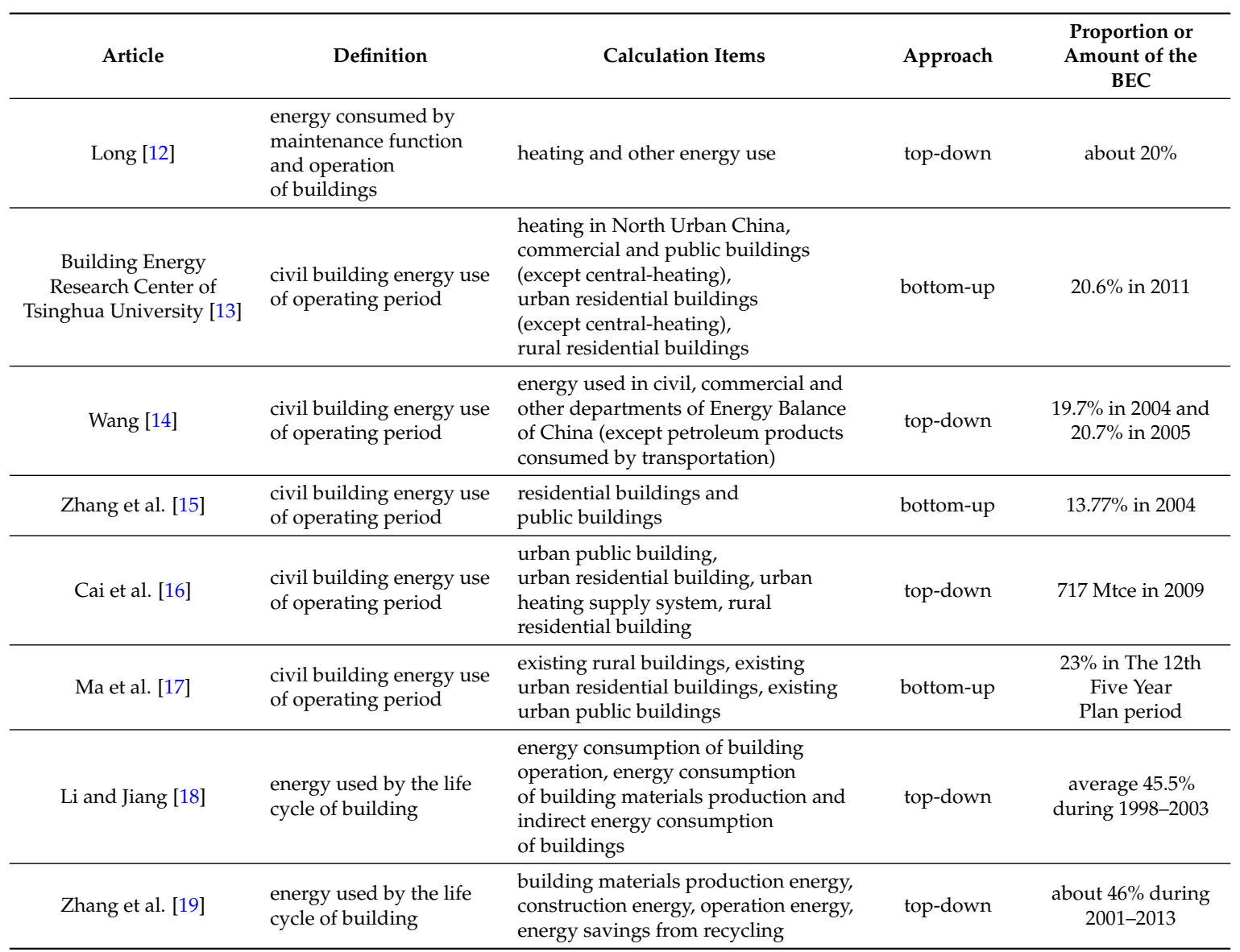

By comparing the calculations of the BEC, the differences of methods firstly come from the distinct definitions, which result in additional items being calculated. The BEC from a life cycle perspective includes energy consumption of materials and construction besides building operation [18,19]. Then, in China, there are two methods to calculate the BEC. One is a macro-statistical method that is a top-down approach to collect the building-related energy consumption dispersed from China energy statistical database. Although applying the macro-statistical method, previous studies on estimating the BEC still have different energy consumption sectors and data sources [14,16]. The other is a bottom-up approach that is a micro-statistical method to analyse the BEC. Unfortunately, at this stage, China has a lack of continuous official data of the BEC on the micro level. The huge gap between definition and method of the BEC would mislead the policy makers by providing conflicting and confusing statistics. In 2010, buildings accounted for 32\% of total global final energy use; in the European Union, buildings accounted for about $40 \%$ of final energy consumption [20]. However, in China, the total amount of the BEC is still uncertain, and the proportion of the BEC also fluctuates due to different models and methods. Thus, it is urgent to research on differentiating and analyzing the shortcomings of previous methods to establish an appropriate method definitely revealing the actualities of the BEC as much as possible. Considering the existed statistical system, the data of the BEC should be collected from other sectors in the Energy Balance. In addition, the building life-cycle assessment mixes energy use of construction, materials, and operation together so that it is hard to make targeted measures for energy saving. Therefore, this paper adopts the definition of civil building 
energy use of the operating period, in order to exclusively reflect the BEC actuality, and this definition can also evaluate the benefits of the pertinent policy.

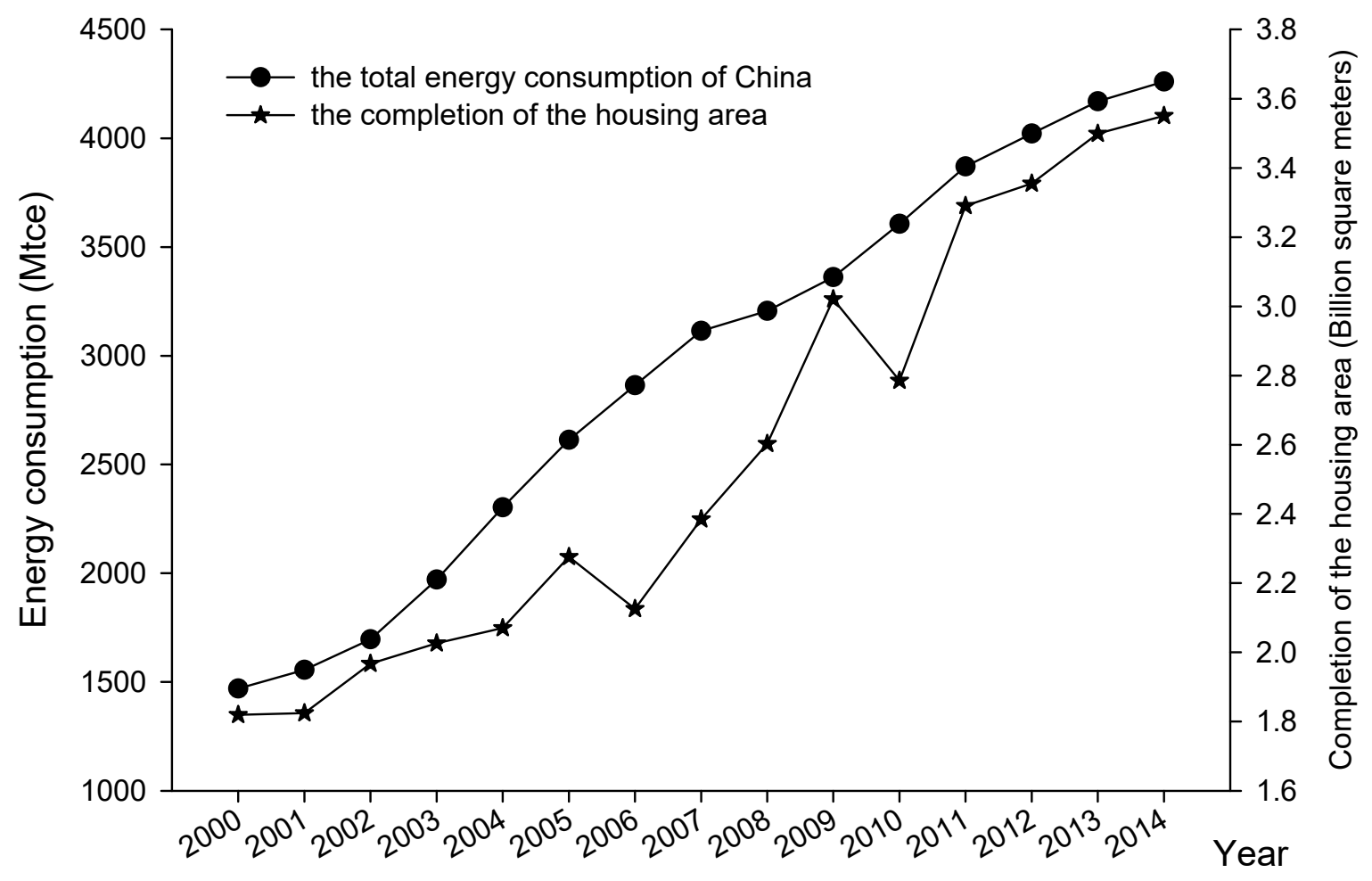

Figure 2. The Energy Consumption and the building completion area in China during 2000-2014.

The BEC data is the basis of building energy efficiency. It is beneficial for policymakers to develop appropriate energy saving policies. Therefore, a statistical method clarifying the present situation of the BEC in China needs to be established. The method, applying top-down approach, primarily explores the interaction between the energy sector and the macro-economy. The denotation of the method is to provide the basis for policy-making as well as to untangle some misunderstanding with energy consumption in the building sector in China. From this method, a clear idea about the current situation of energy consumption relating to buildings in China is obtained. The clear understanding of the BEC is more helpful to investigate the effects of environmental policy.

Given the importance of the building energy and the calculation method on the amount of the BEC in the existing literature, the findings of the current study are expected to enrich this pool of a unifying accounting method surrounding building energy consumption and give the energy consumption of buildings close to the fact. This study proposes that there exists discrepancy among previous studies and that the perspective of building operation is more propitious to institute targeted policies than the life-cycle perspective. The objective of this study is to develop a statistical method of energy only consumed by building running. In particular, even though the method underestimates the amount of building operating energy, part of the ambiguity is eliminated.

To achieve these objectives, a method on the macroscopic view is established. The following section (Section 2) compares the two definitions of building energy consumption and Section 3 establishes a proper model estimating building operational energy consumption. The rest of the paper is arranged as follows. The energy consumption situations of buildings in China during 2000-2013 are revealed by employing the given model in Section 4 . Around the results above, characteristics of building energy consumption of China and the reasonableness of the established model are further discussed and analyzed in Section 5. Finally, the central conclusions are shown in Section 6. 


\section{The Analysis of Concept of Building Energy Consumption}

\subsection{The Definition of Building Energy Consumption}

There are two kinds of definitions of building energy consumption in the existed research. One is the operation of the BEC energy which is expended in maintaining indoor environments and performing building equipment such as heating and cooling, air conditioning, lighting, household appliances, office equipment, hot water supply, cooking, elevator, ventilation and other operating appliances. The other is life cycle energy of buildings. The total life cycle energy of buildings includes both embodied energy and operating energy. The embodied energy refers to being used in building materials during all processes of production, on-site construction, and final demolition and disposal [21,22]. It means that all energy is used in buildings' life cycles, such as energy used in the production of construction materials, building construction, building operational phase and building demolition.

\subsection{The Distinction Between Operating Energy and Life Cycle Energy}

The operating energy is consumed by all activities related to the usage of the buildings. The operating energy consumption is influenced by the using habits of the occupants and the efficiency of equipment in the buildings, while the embodied energy is expended in the initial construction, maintenance, renovation, and demolition. The embodied energy consumption depends on reducing material use, selection of materials with a lower embodied carbon and energy intensity [23]. The embodied energy is buried in the entire process of buildings' utilization, and energy can be saved by improving production and technology, reducing energy intensity and so on.

At present, the embodied energy has triggered more and more concerns and the definition of life cycle energy is applied to analysis the BEC. However, operating energy and embodied energy are all covered by the life cycle energy so that the life-cycle BEC conceals the energy saving effect of efficient equipment and appliances. Meanwhile, the policy efficiency of energy conservation aiming at the operating stage is obscured by embodied energy. In addition, the current emphasis shifting to embodied energy attracts more interest in industrial technology improvements; it ignores the potential for curbing operating energy. Therefore, it is difficult to distinguish the policy efficiency on either operating energy conservation or embodied energy conservation by the statistical method of life-cycle BEC. In order to present a clear and integrated image of the BEC for policymakers, building operating energy consumption is used to establish the statistical method in this study.

\section{The Statistical Method of the Building Operational Energy Consumption}

\subsection{The Type of Building}

In China, the buildings can be classified as industrial buildings and civil buildings, and civil buildings are divided into residential buildings and public buildings. The public buildings include the office buildings, commercial buildings (shopping malls, emporiums), tourism buildings (hotels, entertainment), buildings of science and education, cultural and health, communication buildings (telecommunications, communications, broadcasting station) and transportation buildings (airport, station construction) (see Table 2) [24].

Table 2. The classification and the definitions of civil buildings in China.

\begin{tabular}{ll}
\hline Types of Buildings & Definitions \\
\hline The civil building & General term of the buildings for people living and public activities \\
The residential building & The buildings for people living \\
The public building & The buildings for people of various public activities \\
\hline
\end{tabular}


According to the definition of operating energy consumption and the classification of national economic industries, we can find that four industries in the Energy Balance Sheet of China are involved in the energy consumption of the civil buildings. They are Transport, Storage and Post, Wholesale, Retail Trade and Hotel, Restaurants, Residential Consumption (Urban, Rural) and Others (see Table 3) [25].

Table 3. The industry sector in the Energy Balance Sheet related to building energy.

\begin{tabular}{lll}
\hline Type of Building & & Industry sector \\
\hline \multirow{3}{*}{ Public buildings } & Commercial buildings & Wholesale, Retail Trade \\
\cline { 2 - 3 } & Transportation buildings & Transport, Storage and Post \\
\cline { 2 - 3 } & Tourism buildings & Hotel, Restaurants \\
\cline { 2 - 3 } & Office buildings and others & Others \\
\hline Residential buildings & & Residential Consumption \\
\hline
\end{tabular}

\subsection{The Calculation Method}

The statistical reporting system is implemented for Chinese energy consumption collection. Firstly, by the Statistics Law of the People's Republic of China, the State Statistical Bureau has developed a system of energy statistics. The system of energy statistics includes the production, purchase, consumption and inventory of main energy products. Secondly, various provinces and cities determine for themselves the investigation method of Energy Balance Sheet and Consumption of Energy by Sector. Finally, the State Statistical Bureau collects and gathers all the data submitted by the provinces, autonomous regions, and municipalities.

When the data of energy consumption was collected, because of the system of energy statistics, the energy consumption, which includes the building energy use, is all submitted by business enterprises and units. The BEC is mixed together into the energy consumption of various industry sectors. If using the existed macro statistics, the BEC needs to be calculated by filtering four industries of Energy Balance Sheet. Across all industries of the Energy Balance Sheet, it is highly controversial whether the energy consumption of industrial buildings should be calculated as building energy. On one hand, from the perspective of building operation, comparing with the energy use of industrial production, the amount of industrial building operating energy is relatively small. On the other hand, accounting for the building energy use is aimed to lay the foundation for the pursuit of effective energy saving potentials. Industrial buildings are constructed for the purpose of production, like making cars, manufacturing computers, etc. The energy consumption in such buildings, therefore, should not be the BEC by definition. Furthermore, in other countries, the energy consumption of industrial buildings is excluded from the BEC. Accordingly, the energy use of the industrial buildings is not on the list in this paper.

The civil buildings are categorized into the residential buildings and the public buildings. The energy, used in the residential buildings, is consumed by temperature adjustment, lighting, cooking, household appliances inside the buildings, etc. Rural residential building and urban residential building have different ways of energy consumption. Moreover, most of the living fuel in the residential buildings of Chinese rural areas usually depends on non-commercial energy resources such as straw, firewood, etc. Therefore, non-commercial energy consumption is also calculated in this method. The energy use of public buildings is dispersed in various sectors. Furthermore, the concentration of heat supply of the buildings was usually taken into consideration in previous studies for its vast energy consumption $[17,19]$. However, in this paper, the energy consumption of central heating is not extra added to the energy consumption of buildings because, if adopting the Energy Balance sheet of China, the central heating has been included. With the combination of the energy 
statistics system and the existing data sources, the method of residential buildings energy consumption can be expressed as

$$
N B E=R E+P E+N C E,
$$

where NBE refers to national total energy consumption in the building operation process; RE represents energy used in the residential buildings; PE stands for energy consumption of the public buildings; NCE indicates the non-commercial energy resources consumed in the rural areas, such as straw, firewood, etc. Due to data accessibility and inspired by the previous studies, energy consumption of residential buildings can be calculated by:

$$
\begin{gathered}
R E=R C-G R C-95 \% \times D R C, \\
P E=W R H R C+O S C-95 \% \times G R C-35 \% \times D R C,
\end{gathered}
$$

where RC refers to final energy of residential consumption that is from China's Energy Balance Sheet; GRC denotes gasoline consumption of corresponding sectors; DRC indicates the diesel oil consumed in corresponding industries; WRHRC represents energy consumed in Wholesale, Retail Trade, Hotel, Restaurants, and Other industry; and OSC indicates energy used in the Other industry.

Wang [14] stated that the oil of private automobiles was accounted for in the main consumption of petroleum products in residents' life, so all gasoline and ninety-five percent of diesel oil are used by transportation in the residential consumption. This calculation method is also adopted in some studies [25,26], while other studies regard another proportion of gasoline and diesel consumption as transportation energy [27-29]. Considering the main application of gasoline and diesel oil, they are not necessary energy of buildings. In this method, we completely remove all oil product consumption from industries. In some previous methods, electric power consumption of the Transport, Storage and Post industry was deemed to make contributions to energy use of public buildings [16,26]. However, with the development of railway electrification and the increasing application of high-speed EMU (Electric Multiple Units), the electricity consumption of EMU contributes the largest part in electric power consumption of the Transport, Storage and Post industry. Since the central heating mode is widely used in the buildings of the Transport, Storage and Post industry, we regard thermal consumption as the BEC of the Transport, Storage and Post industry. In conclusion, energy consumption of residential buildings and public buildings can be calculated by the following equation:

$$
\begin{gathered}
R E=R C-G R C-D R C, \\
P E=T S P H C+W R H R C+O S C-G R C-D R C,
\end{gathered}
$$

where TSPHC refers to heating power consumed by buildings of the Transport, Storage and Post industry. Compared with previous studies, the innovation and contribution of this method mainly lies in the building use of non-commercial energy, eliminating all proportions of gasoline and diesel oil and including thermal consumption of the Transport, Storage and Post industry instead of electric power consumption. Furthermore, this method unifies the data source by using final energy consumption of the Energy Balance Sheet.

\subsection{Data}

The calculation method of BEC in China established above is determined by means of the statistical method and available data. The data applied in this article stem from China Statistical Yearbooks and Energy Balance of China Energy Statistical Yearbooks [30,31]. 


\section{Results}

\subsection{Residential Building Energy}

The residential buildings can provide a place for people's living, including villas, dormitories, apartments, etc. The residential consumption denotes that, in daily life, consumption is to meet the needs of the residents and their family members. Therefore, the consumption in the residential buildings, such as cooking and heating, is also the part of residential consumption. In terms of the Energy Balance Sheet, the residential buildings energy is mainly distributed in the residential consumption sector. On the grounds of Equation (4), Figure 3 presents the energy consumption of residential buildings with traffic energy fully deducted for the period of 2000-2013. Obviously, the upward trend of energy consumption in residential buildings is continuing during 2000-2013, which is partly in association with the rapid urbanization and improvement of living quality. In addition, the energy consumed in the residential buildings of rural areas in China increases rapidly, which is because commercial energy resources have been popularized in the countryside.

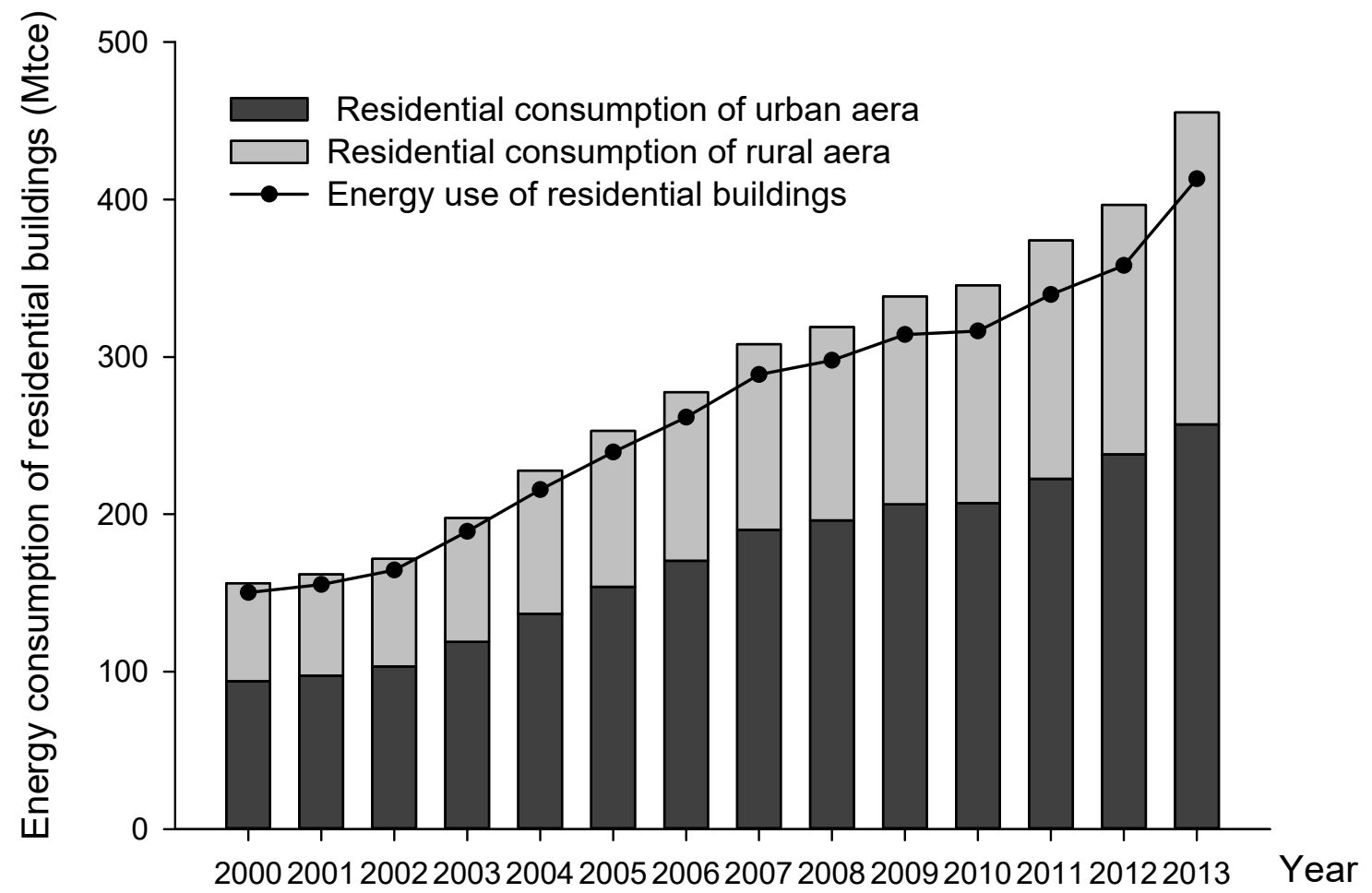

Figure 3. The energy use of residential buildings in China during 2000-2013.

\subsection{Public Building Energy}

In light of the fact that public buildings exist in many fields, by National Economical Industry Classification, we collect the energy, used in the public buildings, from the Transport, Storage and Post industry, Wholesale, Retail Trade and Hotel, Restaurants industry, and the Others industry of the Energy Balance sheet.

\subsubsection{Building Energy of Transport, Storage and Post Industry}

Due to electric power of building use being indistinguishable from the power consumption of railway transportation, we only regard thermal consumption as building energy of the Transport, Storage and Post industry. During 2000-2013, the thermal consumption of this industry has been changed (see Table 4). 
Table 4. The electric power consumption of the Transport, Storage and Post industry in China (2000-2013).

\begin{tabular}{|c|c|c|c|c|c|c|c|c|c|c|c|c|c|c|}
\hline Year & 2000 & 2001 & 2002 & 2003 & 2004 & 2005 & 2006 & 2007 & 2008 & 2009 & 2010 & 2011 & 2012 & 2013 \\
\hline TSPHC (10000tce) & 25.36 & 28.54 & 27.65 & 29.10 & 41.67 & 36.21 & 55.73 & 55.80 & 61.94 & 50.78 & 55.85 & 67.82 & 77.25 & 78.08 \\
\hline
\end{tabular}

\subsubsection{Building Energy of Wholesale, Retail Trade, Hotel, Restaurants, and Others industry}

In the service industry, how much gasoline and diesel is consumed by buildings or transport is still subject to be verified. For guaranteeing the purity of buildings energy, both gasoline and diesel oil are entirely excluded from the industrial final energy consumption. The results are shown in Figure 4.
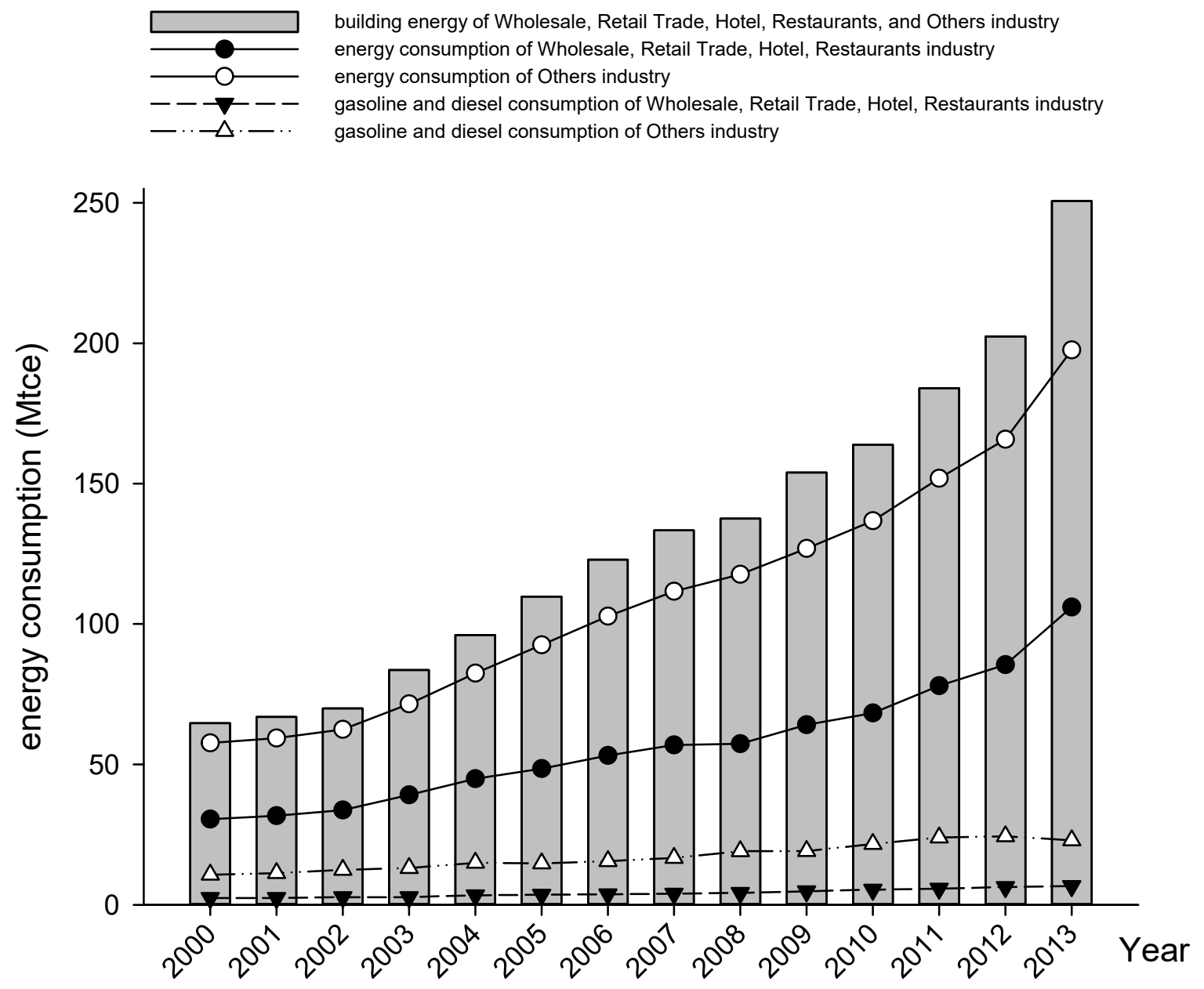

Figure 4. Energy consumption of Wholesale, Retail Trade, Hotel, Restaurants, and Other industries in China (2000-2013). 


\subsubsection{Total Public Building Energy}

The total energy consumption of public buildings in China can be obtained by adding up the values of energy consumption in the two preceding parts. The public building energy consumption increases over time (see Figure 5). Comparatively, public building energy in the Transport, Storage and Post industry accounts for only a small proportion of total public building energy.

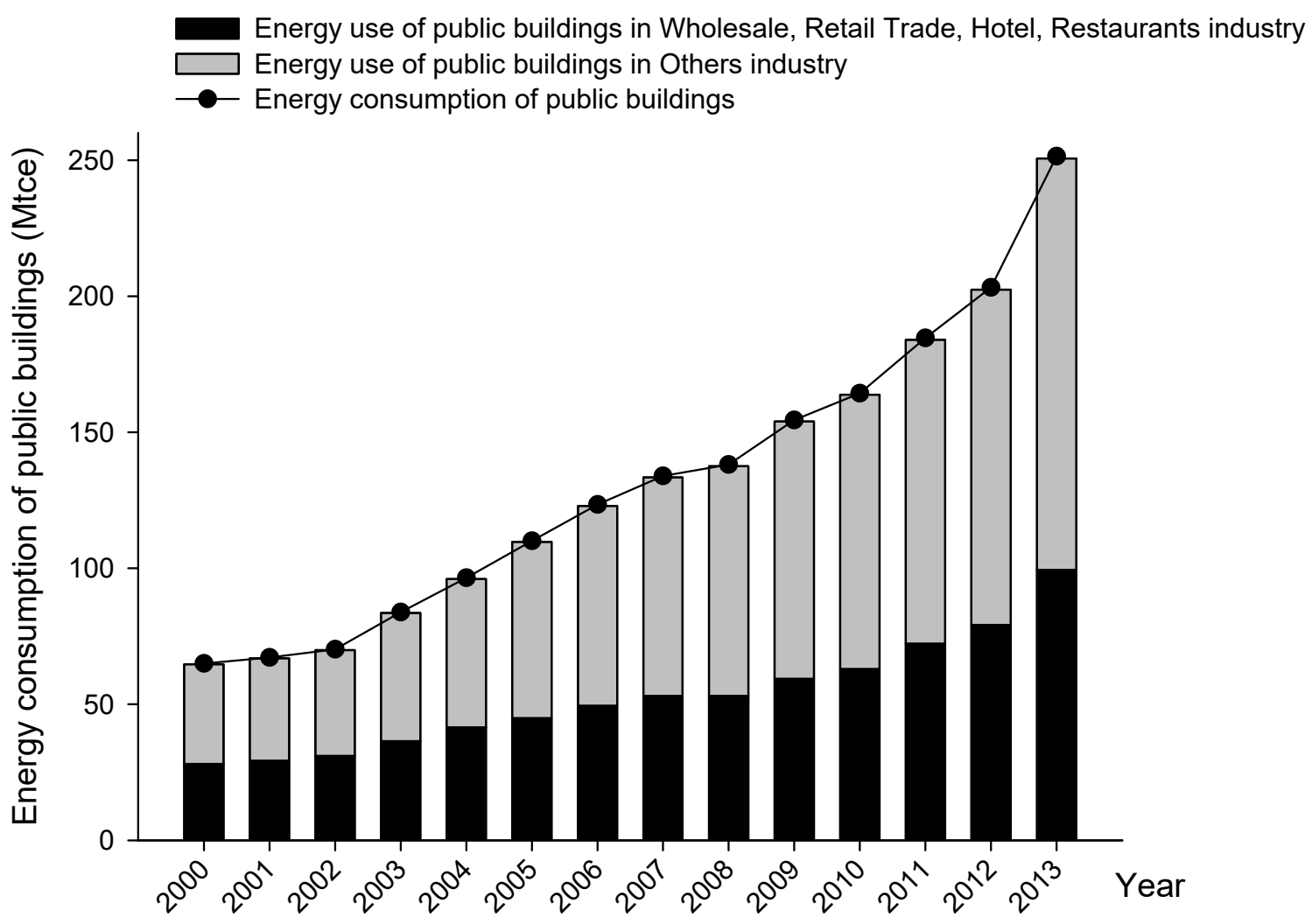

Figure 5. The energy consumption of public buildings in China during 2000-2013.

\subsection{Non-Commercial Energy}

In general, commercial energy refers to those national energy products in which all or most of it enters into the commodity market for transactions, such as fossil fuels (coal, oil and natural gas), nuclear energy, and hydropower. While the energy products, self-produced, self-collected, and self-consumed, are non-commercial energy such as fuel wood, straw and methane. Because Energy Balance of China does not include non-commercial energy, this paper, exclusively or additionally, collects the non-commercial energy consumption of China. The non-commercial energy consumption is considered; and the use of wood and straw is decreasing while the biogas use increases (see Figure 6). 


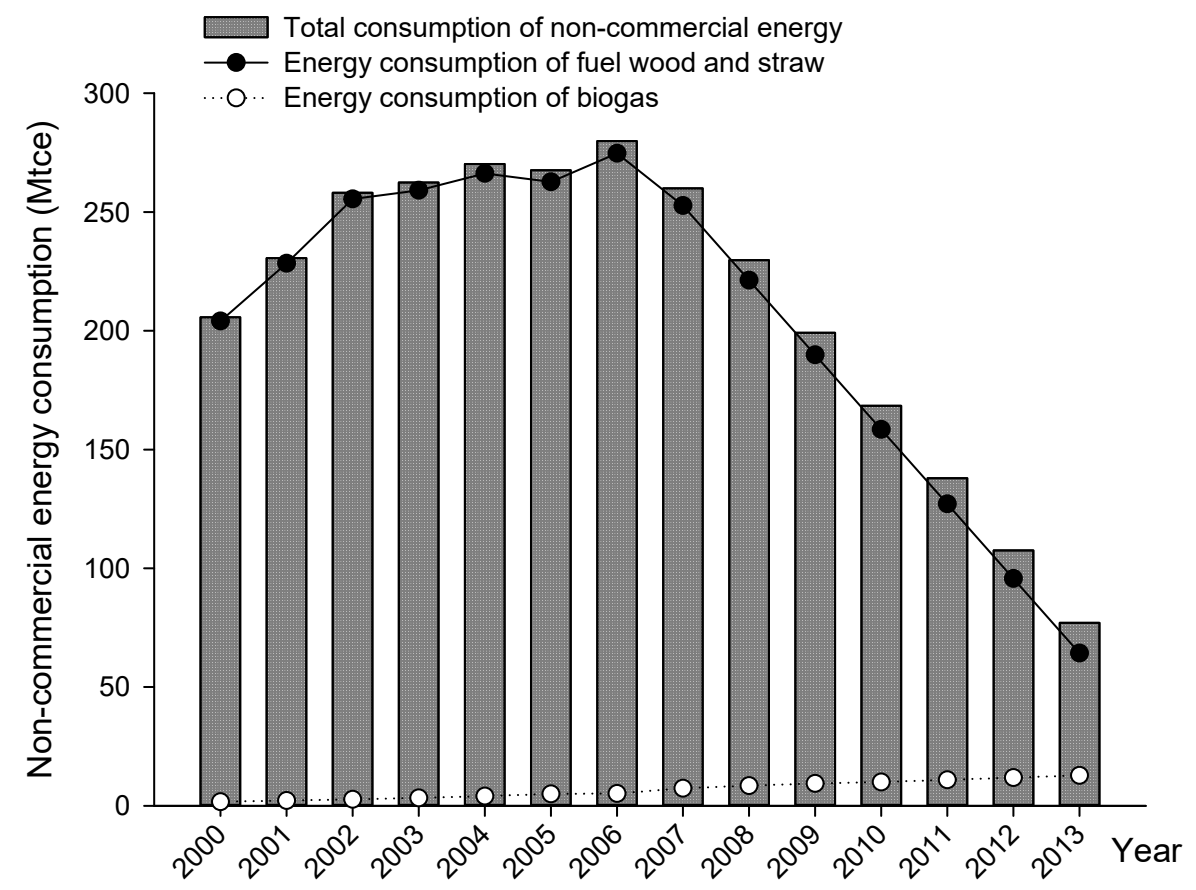

Figure 6. Non-commercial energy consumption in China (2000-2013).

\subsection{Total Building Energy}

The building energy consumption consumed in the running process can be determined by aggregating the results of Sections 4.1-4.3. The BEC in China has experienced an uninterrupted growth from 420.89 Mtce in 2000 to 741.57 Mtce in 2013, as shown in Figure 7. During 2008-2012, the total amount of building energy use slightly decreases along with non-commodity energy consumption reduction.

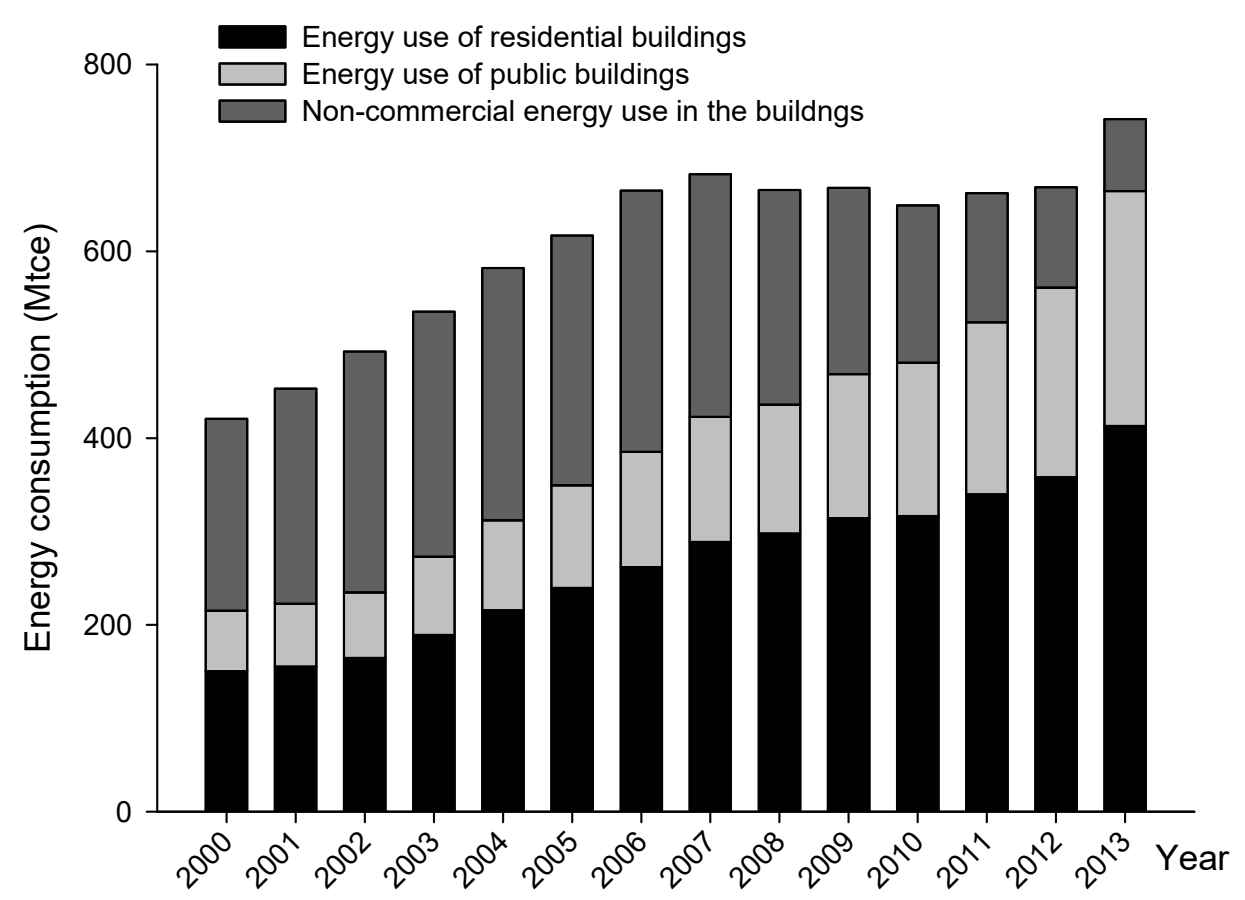

Figure 7. The total energy consumption in China's building sector (2000-2013). 


\section{Discussion and Analysis}

\subsection{National Building Energy Consumption}

Figure 8 presents the energy consumption of buildings in comparison with China's final energy consumption and final energy consumption including non-commercial energy over the period of 2000-2013.

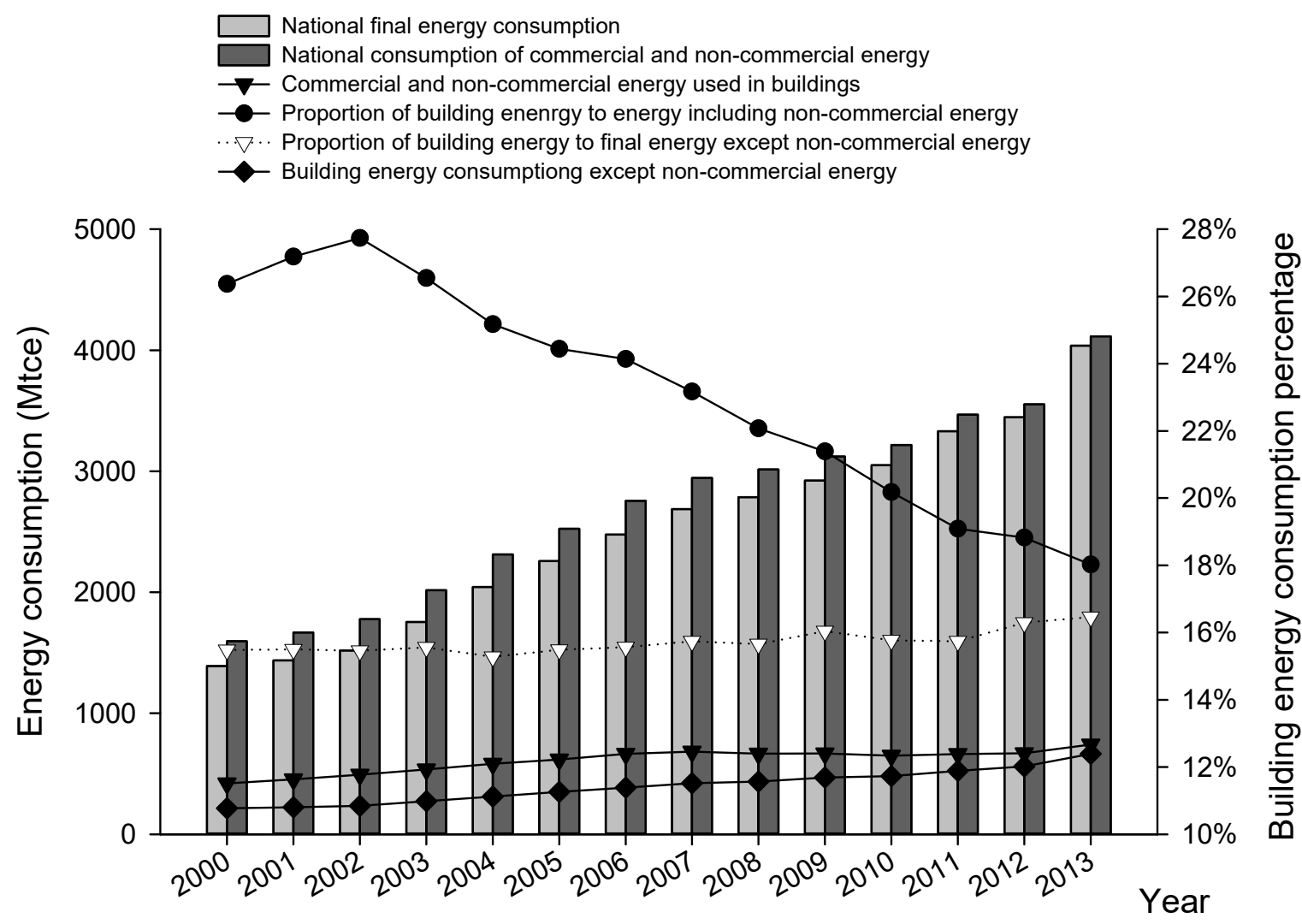

Figure 8. Energy consumption of buildings and its proportion in China (2000-2013).

The final energy consumption refers to the last part of energy consumption or energy obtained by the entrance of terminal energy equipment. According to China's statistics system, the energy consumption of various industries is collected from the final energy used by all sectors the in Energy Balance of China. However, the energy statistics of the Energy Balance Sheet just list commercial energy. The final energy including non-commercial energy is shown in Figure 8. Obviously, the non-commercial energy consumption is decreasing with popularization of commercial energy and cost improvement of access to non-commercial energy, so that the proportion of building energy to final energy including non-commercial presents a declining trend. To explore the interaction between energy consumption and economy, the top-down approach is applied. The definition of building operating energy is beneficial to investigate energy saving behaviors and habits. In fact, the net building consumption accounts for merely 15-16 percent with respect to the final energy consumption in China. Overall, the total amount of building energy makes the foundation for building energy conservation. It is significantly important to pay more attention to building sector's energy situation, and based on which, to achieve the target of energy saving and emission reduction and ensure the energy security of China. 


\subsection{Energy Consumption of Central Heating in Buildings}

In terms of energy composition, coal, petroleum products, natural gas, liquefied natural gas, heat, electricity and other energy would be captured in the Energy Balance of China. As the heat has already been included in the final energy, it is unnecessary that the energy consumption associated with central-heating is counted in the building energy consumption. Taking China's Energy Balance Sheet (2013) for example (see Table 5), the energy supplied by a heat supply enterprise has been added in the final energy. Moreover, we can find out that the most heating supply is used by the Industry sector. Therefore, applying a top-down approach, the energy consumption of central heating calculated again results in an excessive amount of building energy that does not accord with the truth.

Table 5. Part of 2013 Energy Balance of China (standard quantity).

\begin{tabular}{ll}
\hline Item & Heat (Mtce) \\
\hline Input (-) or Output (+) of Transformation & $\mathbf{1 2 4 . 3 3}$ \\
Thermal Power & -16.54 \\
Heating Supply & 123.48 \\
Recovery of Energy & 17.39 \\
\hline Loss & $\mathbf{1 . 4 3}$ \\
\hline Total Final Consumption & $\mathbf{1 2 2 . 9 0}$ \\
Agriculture, Forestry, Animal Husbandry, Fishery and Water Conservancy & 0.04 \\
Industry & 89.21 \\
Construction & 0.27 \\
Transport, Storage and Post & 0.78 \\
Wholesale, Retail Trade and Hotel, Restaurants & 1.73 \\
Others & 3.09 \\
Residential Consumption & 27.78 \\
\hline
\end{tabular}

\subsection{Structural Composition of Energy Consumption in Buildings}

Figure 9 depicts the composition of China's energy consumption in the buildings from 2000 to 2013. Obviously, residential building energy and non-commercial energy predominate in building energy. The two proportions present exactly opposite variation trends. As more commercial energy has been used in rural areas, the percentage of non-commercial energy decreases continuously, having dropped to $10.40 \%$ in 2013. Specifically, the proportion of public building energy experiences an upward trend, gradually increased from $15.38 \%$ in 2000 to $33.84 \%$ in 2013; it is a potential field to effectively reduce energy consumption in future.

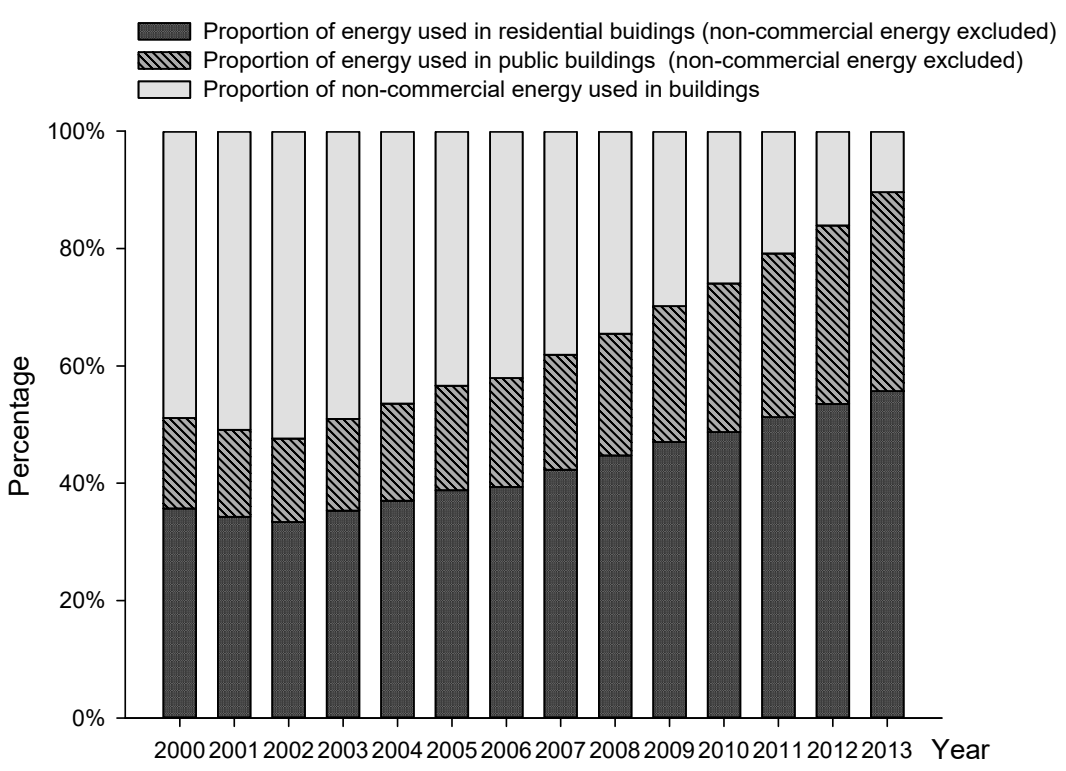

Figure 9. Energy consumption of buildings and its proportion in China (2000-2013). 


\subsection{The Environmental Effects of Building Energy}

Buildings are major consumers of energy. Only the energy consumption of the residential building sector ranked second after the industry sector [22]. The environmental effects of energy consumption of 15 percent or 45 percent of the final energy lie between two extremes. By improving building energy efficiency, the European Community research has found that carbon emissions from buildings would be reduced by 22 percent [32]. Promoting building energy efficiency will help with achieving goals for reducing carbon emissions as well as improving the energy performance of new and existing buildings. The overvalued building energy will mislead the judgement of its carbon and even pollution emission. Therefore, the environmental problems associated with building energy consumption are widely misunderstood.

\subsection{Building Energy Saving}

The Building energy saving refers to low operation energy consumption and high energy efficiency, by a procedure of planning, design, construction and maintenance, to meet the prescriptive function requirements of buildings and the quality of the indoor environment through the technical measures and management methods [33]. Thus, the goal of building energy efficiency is to reduce operating energy. Hong et al. [34], from the perspective of life-cycle, use an input-output model to simulate the embodied energy consumption of the construction industry in Guangdong province. They find that the embodied and operational phases together account for nearly $98 \%$ of the total energy consumption. However, most energy consumption belongs to the buildings sector. It is too difficult to reflect the role of building energy efficiency in reducing energy consumption. From an operational perspective, the proportion of BEC in total energy consumption is less than those in developed countries. BEC is expressive of the character and development of the service industry and residents' life.

\section{Conclusions}

The huge energy consumption of China challenges its energy security and sustainable development along with increasing desire for indoor comfort. Meanwhile, in order to perform the duties of reducing emissions, building energy efficiency is expected to play a significant role in addressing energy problems in China. However, the blurry data about BEC brings blindness to the national building energy conservation policy. Therefore, data verification of BEC becomes extremely urgent. This paper is helpful to clear up misunderstandings about the building energy situation. Furthermore, it is easier for policymakers to assess the environmental effects of BEC and the function of energy saving policy. A model of building energy is established in this paper to respond to the controversy and dispute the exact amount of BEC. To ensure energy security and sustainable development, the BEC is one of the keys to energy saving and emissions-reduction. Therefore, this study has been presented to determine the net energy consumption in buildings from a building operating perspective. By the comprehensive analysis carried out above. We obtain the following conclusions:

1. China's BEC without redundancy only accounts for 15-16 per cent of the final energy, rather than about 45 per cent, which is caused by including the energy use of material production, construction and so on. The life cycle building energy is not beneficial to the policy targeted at conservation in a stage of building life cycle.

2. Considering the policy relevance, the blurry data is eliminated as much as possible. In particular, the central heat supply of buildings that was repeatedly accounted for in prior studies is deducted. Overall, the proportion of BEC to total energy consumption in China is less than those in developed countries.

3. The residential BEC dominates the use of building energy in China, and the major conservative measure is improving the habit of energy usage. The percentage of public BEC to building energy is also increasing while the non-commercial energy consumption has obviously reduced. 
Above all, the building energy consumption is underestimated; but, given that redundancy and imprecise accounting are deducted, all that remains is consumed by buildings. Meanwhile, more efficient amounts of building energy consumption are collected and shared, with regard to laying the foundation for energy saving in China.

Acknowledgments: The authors would like to thank Chen Su-Mei, Yang Sheng, Yang Hua-Lei, Qiu Lu-Yi, Liu Li, Ou Jia-Jia, and all other colleagues from both the China Agricultural University and Jinan University, for all their warm support, constructive suggestions and pertinent comments. This project is supported by the National Natural Science Foundation of China (Grant Nos. 71273261 and 71573258), and the China National Social Science Foundation (No. 15ZDA054).

Author Contributions: Ling-Yun He is a full professor of energy economics and environmental policies. Wei Wei is a research associate supervised by Ling-Yun He. The authors contributed equally in the project. Ling-Yun He conceived the whole project. Wei Wei calculated and analysed the results under Ling-Yun He's supervision. Ling-Yun He and Wei Wei co-wrote the manuscript.

Conflicts of Interest: The authors declare no conflict of interest.

\section{References}

1. The Energy Information Agency (EIA), International Energy Statistics. Available online: http:/ / www.eia. gov/cfapps/ipdbproject/IEDIndex3.cfm?tid=44\&pid=44\&aid=2 (accessed on 20 April 2017).

2. Pérez-Lombard, L.; Ortiz, J.; Pout, C. A review on buildings energy consumption information. Energy Build. 2008, 40, 394-398.

3. The Internationaly Energy Agency (IEA). Energy Balances of non-OECD Countries 2011; OECD Publishing: Paris, France, 2011.

4. Lin, B.; Liu, H. China's building energy efficiency and urbanization. Energy Build. 2015, 86, 356-365.

5. Shen, L.; He, B.; Jiao, L.; Song, X.; Zhang, X. Research on the development of main policy instruments for improving building energy- efficiency. J. Clean. Prod. 2016, 112, 1789-1803.

6. Hong, T. A close look at the China Design Standard for Energy Efficiency of Public Buildings. Energy Build. 2009, 41, 426-435.

7. Chinese, U.S. Companies Launch Fund to Promote Energy Efficient Buildings. News, Global Edition. 2015. Available online: http://news.xinhuanet.com/english/2015-09/17/c_134633961.htm (accessed on 20 April 2017).

8. The Energy Information Agency (EIA), Residential Energy Consumption Survey. Available online: https:/ /www.eia.gov/consumption/residential/data/2015/ (accessed on 20 April 2017).

9. The Energy Information Agency (EIA), Commercial Buildings Energy Consumption Survey. Available online: https:/ / www.eia.gov/consumption/commercial/data/2012/ (accessed on 20 April 2017).

10. Ministry of Energy and Mineral Resources. Handbook of Energy and Economic Statistics of Indonesia, 2012. Available online: http:/ / prokum.esdm.go.id/Publikasi/Handbook\%20of\%20Energy\%20\&\%20Economic\% 20Statistics\%20of\%20Indonesia\%20/Handbook\%20of\%20Energy\%20\&\%20Economic \%20Statistics\% 20ind\%202012.pdf (accessed on 20 April 2017).

11. Yang, X.; Wei, Q.P.; Jiang, Y. Study on statistical method for building energy consumption. Building Energy Effic. 2007, 35, 7-10.

12. Long, W.D. Building energy consumption ratio and building energy efficiency target. China Energy 2005, 27, 23-27.

13. Building Energy Research Center, Tsinghua University. 2013 Annual Report on China Building Energy Efficiency; China Architecture and Building Press: Beijing, China, 2013.

14. Wang, Q.Y. Research on statistics and calculation of building energy consumption in China. Energy Conserv. Environ. Prot. 2007, 8, 9-10.

15. Zhang, H.B.; Lu, S.H.; Ni, D.L. Research on statistical model and method of building energy consumption. Build. Sci. 2008, 24, 19-24.

16. Cai, W.; Ren, H.; Cao, S. Decomposition analysis of driving factors for building energy consumption in china. Nat. Environ. Pollut. Technol. 2014, 13, 203-210.

17. Ma, M.; Yan, R.; Du, Y.; Ma, X.; Cai, W.; Xu, P. A methodology to assess China's building energy savings at the national level: An IPAT-LMDI model approach. J. Clean. Prod. 2017, 143, 784-793. 
18. Li, Z.J.; Jiang, Y. Pondering over the Situation of Domestic Generalized Building Energy Consumption. Arch. J. 2006, 7, 30-33.

19. Zhang, Y.; He, C.Q.; Tang, B.J.; Wei, Y.M. China's energy consumption in the building sector: A life cycle approach. Energy Build. 2015, 94, 240-251.

20. Berardi, U. A cross-country comparison of the building energy consumptions and their trends. Resour. Conserv. Recycl. 2016, doi:10.1016/j.resconrec.2016.03.014.

21. Dixit, M.K.; Fernández-Solís, J.L.; Lavy, S.; Culp, C.H. Identification of parameters for embodied energy measurement: A literature review. Energy Build. 2010, 42, 1238-1247.

22. Ramesh, T.; Prakash, R.; Shukla, K.K. Life cycle energy analysis of buildings: An overview. Energy Build. 2010, 42, 1592-1600.

23. Ibn-Mohammed, T.; Greenough, R.; Taylor, S.; Ozawa-Meida, L.; Acquaye, A. Operational vs. Embodied Emissions in Buildings-A Review of Current Trends. Energy Build. 2013, 66, 232-245.

24. Ministry of Construction of the People's Republic of China. Code for Design of Civil Buildings; China Architecture and Building Press: Beijing, China, 2005.

25. $\mathrm{Xu}, \mathrm{A}$. Building energy consumption and energy saving in Hubei. Contemp. Econ. 2011, 11, 96-99.

26. Lin, X.S.; Peng, J.H.; Jiang, H. Statistics and calculation of building energy consumption in Chongqing. Build. Energy Conserv. 2008, 36, 55-57.

27. Ni, D.L. Some problems in the statistical work of building energy consumption in Shanghai. Electr. Power Energy 2008, 29, 163-166.

28. Fang, D.Q.; Zhang, H.; Wu, K. Energy consumption of public buildings in the city of Shanghai. Estim. Anal. Environ. Sci. Manag. 2012, 6, 41-46.

29. Zhuang, Z.; Xu, Q.; Tan, H.W.; Qiu, X.L. Study on energy consumption calculation method of urban civil buildings based on energy statistics. Arch. Sci. 2011, 27, 19-22.

30. National Bureau of Statistics. China Statistical Database: 2000-2013. Available online: http:/ /www.stats.gov. $\mathrm{cn} / \mathrm{tjsj} / \mathrm{ndsj} /$ (accessed on 20 April 2017).

31. National Bureau of Statistics. China Energy Statistics Yearbook: 2000-2013. Available online: http: / / tongji.cnki.net/kns55/Navi/HomePage.aspx?id=N2016120537\&name=YCXME\&floor=1 (accessed on 20 April 2017).

32. Department of Health. EU directive on the energy performance of buildings. Available online: https://www.gov.uk/government/uploads/system/uploads/attachment_data/file/148604/Final_EU_ Final_Energy_Performance_of_Buildings_Directive.pdf (accessed on 20 April 2017).

33. Ministry of Housing and Urban Rural Development of People's Republic of China. Basic Terminology of Building Energy Efficiency Standards; China Architecture and Building Press: Beijing, China, 2016.

34. Hong, J.; Zhang, X.; Shen, Q.; Zhang, W.; Feng, Y. A multi-regional based hybrid method for assessing life cycle energy use of buildings: A case study. J. Clean. Prod. 2017, 148, 760-772.

(C) 2017 by the authors. Licensee MDPI, Basel, Switzerland. This article is an open access article distributed under the terms and conditions of the Creative Commons Attribution (CC BY) license (http://creativecommons.org/licenses/by/4.0/). 